\title{
Charisma as a Follower-centric, Cognitive-affective Phenomenon: Initial Qualitative Evidence for the Cognitive Dimension
}

\author{
J A S K Jayakody
}

\begin{abstract}
Taking the follower-centric approach to charismatic leadership, this paper explores how followers construct charisma. Based on in-depth data from followers representing members of the Senior Management Team and a task force of an Enterprise Resource Planning (ERP) implementation project of two Sri Lankan business operations, this paper illustrates that followers construct charisma through multiple cognitive processes concurrently. The paper concludes that charisma is a constellation of meanings consisting of leader prototypes, leader archetypes, leader extraordinariness and perhaps even leader group prototypes. Consequently, this paper contributes to the followercentric theory by showing the need and the possibility of taking an integrative approach to charisma.
\end{abstract}

Keywords: charisma, cognitive-oriented paradigm, follower-centric approach, leadership, qualitative study.

\section{Introduction}

The follower-centric approach asserts that '...subordinates' perceptions of their leaders are a central determinant of subordinates' reaction to those leaders' (van Quaquebeke, van Knippenberg \& Brodbeck 2011, p. 368) and advocates that researchers explore the cognition of the follower instead of the leader (Haslam et al.2001) so as to understand the dynamics of charisma. Following this assertion, leadership theorists have borrowed heavily from cognitive psychology-a trend that Lord and Emrich (2001) have termed the cognitive revolution in leadership research and van Quaquebekeet et al. (2011) have recently called 'the cognitive oriented paradigm of follower-centric leadership'. In addition to this cognitive

J A S K Jayakody, $\boldsymbol{P h D}$ is an Associate Professor of the Department of Management \& Organization Studies, Faculty of Management \& Finance, University of Colombo and Head, Research Centre at the Postgraduate Institute of Management. E-mail: jaskjayakody@yahoo.com 


\section{NSBM Journal of Management}

Vol. 1, No. 1, January - June, 2015

oriented paradigm, there are also attempts to explain charisma as an emotional phenomenon (Ladkin 2006, 2008, Wasielewaki 1985).

At present, there are several theories in this approach and each theory explains charisma through a selected cognitive or affective process. For instance, while the leader categorization theory of leadership suggests that charisma is attributed when the leader is perceived as a prototypical leader (Lord, Foti \& De Vader 1984, Lord \& Emrich 2001, Ensari \& Murphy2003, Dickson, Resick \& Hanges 2006, van Quaquebekeet et al.2011), the social identity theory of leadership states that charisma is attributed to the leader due to his/her group prototypicality (Hogg 2001, van Knippenberg \& van Knippenberg 2005, van Knippenberg 2011, Platowetal 2006). On the other hand, the romance of leadership theory takes a completely different stance and argues that performance cues (Meindl 1995, Ensari \& Murphy 2003) are the basis of charismatic attribution. The aesthetic approach to charisma assumes that followers' aesthetic encounter with the leader results in charismatic attribution (Ladkin 2008). Finally, drawing from Jung (1981), another group of researchers (Steyrer 1998, Kociatkiewicz \& Kosteraa 2012, Takala et al. 2012) argues that charisma originates in leader archetypicality.

Contrary to each theory's attempt to explain the follower-centeredness of charisma through a selected cognitive or affective process, the empirical evidence to date indicates a more complex interplay between leader group prototypes and performance cues (Haslam et al. 2001), and leader group prototypes and leader prototypes (Hais, Hogg \& Duck 1997). Jayakody (2008), having noted this contradiction between theory and empirical evidence, postulates that followers attribute charisma through two or more cognitive and affective process concurrently. Subsequently, he conceptualizes charisma as a follower-centric, cognitive-affective construct consisting of three cognitive components and two affective components. He describes three cognitive components as 'Leader Extraordinariness', 'Leader Archetypicality' and 'Leader Group Prototypicality', while 'Reverence with Awe' and 'Love with Enthusiasm' are proposed as constituent affective dimensions. In support of his conceptualization, Jayakody (2008) notes that Weber considers charisma as a followercentric, multi-dimensional phenomenon, citing Weber's reference to subtypes of charisma, its emotionality and his treatment of extraordinariness as an attributional phenomenon.

Accordingly, taking the social constructionist approach, this paper proposes to provide some initial qualitative evidence in support of charisma as a constellation of meanings for a given follower, and thereby conceptualize charisma as a constellation of leader extraordinariness, leader group prototypicality, leader prototypicality and leader archetypicality. The paper employs the recognition-based information processing perspective and Weber's theory of 
charisma as the theoretical basis for this integration in addition to the social constructionist approach. It should be noted that the present paper excludes the affective dimension of charisma as well as the role of performance cues simply due to lack of space.

Accordingly, this study illustrates the need and the possibility of integrating different attribution processes suggested in the follower-centric approach to study charismatic dynamics and contributes to the existing literature on charismatic leadership in several ways. First, this study contributes to the research that treats followership as a research area in its own right (Uhi-Bien et al. 2014) by addressing what Tee, Paulsen and Ashkanasy (2013) called 'omission of follower in leadership studies'. Second, the study brings leader prototypicality, leader group prototypicality, and leader archetypicality and leader extraordinariness into a single framework with the use of recognition-based information processing and Weber's theory of charisma, and provides evidence for the attribution of charisma through several concurrent processes (Hanges, Loard \& Dickson 2000). Consequently, this study establishes a sound theoretical basis for the cognitive dimension of charisma, thereby strengthening the follower-centric approach to charisma. Finally, the paper also provides initial qualitative empirical evidence for this new conceptualization, thus addressing the long-felt need of exploring the follower-centric approach in the day-to-day organizational context through qualitative methods (Yorges, Weiss \& Strickland1999).

The rest of the paper begins with a review of the literature outlining recognition and inferencebased information processing -the underpinnings of the cognitive dimension of charisma. Then, the author discusses leader prototypes, leader group prototypes, leader archetypes and leader extraordinariness emphasizing the possibility of developing an integrative framework of charisma. This is followed by a section on the methodology of the empirical study which takes the form of two case studies. The fourth section presents the results followed by a discussion of the findings. The paper concludes with a brief discussion of implications, limitations and further research.

\section{Literature Review}

\section{Information Processing and Follower-Centric Theories}

The cognitive-oriented paradigm dates back to the early 1980s. During the last three decades, at least three major theories evolved, namely, the social identity theory of leadership (Hogg 2001), the leader categorization theory (Lord et al. 1984) along with the implicit leadership theory (Eden \& Leviatan 1973), and the romance of leadership (Meindl 1995). The notion of 


\section{NSBM Journal of Management}

Vol. 1, No. 1, January - June, 2015

archetypical leader (Steyrer 1998) could also be incorporated in this list although it does not stand alongside the other theories in terms of theoretical sophistication and empirical support.

While the social identity theory of leadership and the leader categorization theory draw their basic premises from what theorists call recognition-based information processing (Holmberg \& Akerblom 2006), inference-based information processing is the foundation of the romance of leadership theory (Ensary \& Murphy 2003).Furthermore, recognition-based information processing is the underpinning of leader archetypes as well as leader extraordinariness.

The leadership theories that draw on recognition-based information processing postulate that followers attribute charisma to leaders in terms of the match between perceived traits and/or behaviors of their leaders and the leader/group prototypes. Accordingly, as discussed below, this process of matching is what is central in charismatic attribution, be it based on leader prototypes, leader group prototypes, leader archetypes or leader extraordinariness.

\section{Leader Prototypes and Leader Group Prototypes}

Prototypes are defined as '...fuzzy sets that capture the features of a particular category of objects, often in the form of representations of exemplary objects... or ideal types' (Hogg \& Terry 2000, p. 123). They are cognitive structures and are stored in the individual's memory. In other words, prototypes represent the normative expectations of people about the features of a particular category of objects. For instance, followers hold fuzzy sets of features of ideal leaders which represent followers' normative expectations of a leader. Four characteristics of prototypes are important in the context of the present study. First, when people interact with other objects these other objects are likely to activate the relevant prototypes. Second, individuals use prototypes to interpret objects with which they interact. Third, prototypes constantly evolve as individuals interact with other individuals, objects and events, and thus the normative expectations about individuals, objects and events evolve constantly. Finally, prototypes do not comprise all the characteristics of particular objects but only the most salient characteristics (van Knippenberg \& van Knippenberg 2005).

In the context of the above discussion, the leader categorization theory and the social identity theory of leadership which ascribe a central role to prototypes view the leader as one who matches the prototypes, either leader prototypes in the case of the leader categorization theory or group prototypes in the case of the social identity theory of leadership. Further, both theories accept that leaders are likely to activate prototypes that followers when they interact with the leader (for group prototypicality, see van Knippenberg and van Knippenberg 
[2005], Giessner, van Knippenberg and Sleebos [2009], for leader prototypicality, see van Quaquebeke et al. [2011], Keller [1999]). Both theories also suggest that the leader who is perceived to be most prototypical, i.e., who is perceived to match their ideal, be it the leader or the group member in the case of leader prototypicality and leader group prototypicality respectively, as being effective and that the followers are likely to attribute charisma to this most prototypical person (van Knippenberg 2011). Finally, both theories posit that a leader does not have to match all attributes of the category; instead he has to match only the most salient attributes of the category (i.e., leader or group category).

In spite of these similarities between these two theories, they also differ from each other in some significant ways. The first and the most important difference is the type of prototypes they refer to, which is leader group prototypes in the social identity theory of leadership and leader prototypes in the leader categorization theory. In the case of leader group prototypes, the prototype refers to the social group to which the leader and follower both belong, and in the case of leader prototypes, the prototype refers to leaders. Consequently, leader group prototypes embrace the traits and behaviours that followers expect from their (ideal) group members, while leader prototypes embrace the traits and behaviours that followers expect from their (ideal) leaders. The second difference is that leader prototypicality is believed to be more contextual than leader group prototypicality (Giessner et al. 2009, Dickson et al. 2006, Nye \& Forsyth 1991) because the former is said to vary across persons (Giessner et al. 2009, Nye \& Forsyth 1991), cultures (Dickson et al. 2006, Giessner et al. 2009); and hierarchical levels and target genders (Dickson et al. 2006), although some elements of prototypicality are universally held (Dickson et al. 2006). However, the leader group prototypes are also subject to the influence of salient out-groups at a given point of time (Hogg \& Terry 2000).

\section{Leader Archetypes}

In contrast to the above theories, Steyrer (1998) argues that the root of charisma is archetypes and not prototypes, borrowing from Neuberger's thesis that behind the generic category of leadership there is another more basic dimension called archetypes. Researchers who use archetypes to explain charisma argue that followers are likely to attribute charisma, when the leader is perceived to match their archetypical leader.

Archetypes represent the more unconscious preferences of human beings that are innate, universal and reveal characteristics of humans as a species (Abramson 2007). Furthermore, they are said to develop as a result of human evolution and supersede cultural influences; thus, all human beings across cultures are believed to share the same archetypes (Abramson 2007). 


\section{NSBM Journal of Management}

Vol. 1, No. 1, January - June, 2015

However, archetypes are embodied in and communicated through mythologies (Jung 1981), and thus a particular archetype, while having a more universal character, may also have culturally specific features. For instance, the mother, an archetype, exists across cultures, and the disposition towards the mother may be similar in all cultures, i.e., faith in the mother's tenderness. However, expected traits and behaviors of the mother may vary across cultures. For instance, in Europe, a 'loving and terrible' mother, as Jung (1981) states, may exist in the form of Virgin Mary while in India the same may take the form of Kali whose traits and behaviors differ from those of Virgin Mary.

According to Olsson (2000), Steyrer suggests that charisma can be 'operationalized' in terms of the archetypes such as hero, saviour, father and king. In addition to these four archetypes, Olsson (2000), arguing the need for using female archetypes to study business women, suggests the Xana warrior princess as an archetypical woman manager. Recently, Takala et al. (2012) used archetypes to analyze Obama. The literature however has paid comparatively scant attention to leader archetypes.

As leader prototypes and leader group prototypes are similar in certain ways and are different in some other ways from each other, leader archetypes can also be considered similar to prototypes in several important ways and different in a few other ways. First, leader archetypes are similar to both leader prototypes and leader group prototypes since all three personify the normative expectations of followers. Second, leader archetypes, similar to the other two, are likely to be activated when followers interact with their leaders; and once they become active, followers use them to perceive leaders. Third, like leader prototypes and leader group prototypes, charisma is attributed to leaders based on the similarity between leader archetypes and perceived behaviours and traits of the leader.

However, leader archetypes are different from both leader prototypes and leader group prototypes in several ways. First, archetypes, compared to prototypes, are more unconscious, and thus are likely to be more dormant than prototypes. Second, unlike both leader prototypes and leader group prototypes, leader archetypes possess very specific attributes and are limited in number. Finally, attributes and behaviours considered as archetypical are comparatively more culturally rooted than those embedded in leader prototypes and leader group prototypes.

Due to the fact that archetypes are more unconscious than prototypes, followers are likely to use archetypes less frequently than they use prototypes, be it leader or group, to attributecharisma. Further, unlike leader prototypes, but similar to leader group prototypes which are more likely to be evoked in the context of salient out-groups, a particular archetypical leader 
is likely to be active only in a specific context. For instance, a saviour-like leader may emerge in a crisis more than in other contexts (Takala et al. 2012). Also, just as traits and behaviors embedded in group prototypes are less likely to vary among the followers of a given group, traits and behaviours of the archetypical leader are less likely to vary among the followers in a given culture. In contrast to both leader group prototypes and leader archetypes, different followers of the same group or the same culture may possess different leader prototypes.

\section{Leader Extraordinariness}

Among the four dimensions that the present paper conceptualizes as dimensions of charisma, leader extraordinariness is not the subject of much discussion in the follower-centric approach except to treat charisma, i.e., extraordinariness as an aspect of implicit leadership. Therefore, the follower-centric approach can be said to drop leader extraordinarinessthe most celebrated aspect of charisma in both Weber's writings and in the leader-centric approach. In fact, the concept of leader extraordinariness cannot be dropped from charisma since extraordinariness is a perceptual phenomenon in Weber's work. Weber states that followers attribute charisma to leaders when leaders are '...considered extraordinary and treated as endowed with supernatural, superhuman, or at least specifically exceptional powers and qualities...' (Weber1947, p. 358). According to Jayakody (2008),Weber's use of terms such as 'exceptional', 'supernatural' and 'superhuman' should be taken to mean 'leader's apartness from the ordinary' and uses the term 'extraordinariness' to signify 'the leader's apartness from the ordinary'. Furthermore, he suggests that 'exceptional', 'supernatural' and 'superhuman' imply different levels of extraordinariness.

However, Jayakody's (2008) interpretation of 'extraordinariness' does not do sufficient justice to Weber's use of the same term since charisma means not just an apartness from the ordinary but a 'beyondness' from the ordinary. Thus charisma, based on Weber, can be said to be attributed when the leader is perceived to be transcendental, i.e., beyond being an ordinary human. This interpretation of Weber's work is supported by Williams (1988) when he states that 'supernatural' implies a person who is beyond a human being or more correctly beyond a prototypical human being. Accordingly, leaders can be expected to be attributed with charisma when they exceed followers' normative expectations of leader.

Weber's own writing supports Jayakody's (2008) interpretation of charisma when Weber states that genuine charisma is not a part of normative order (Greenfeld 1985). Conger and his colleagues too support this stance when they state that charisma is attributed when leaders are perceived to '... use unconventional and counter cultural strategies and plans of action' 
NSBM Journal of Management

Vol. 1, No. 1, January - June, 2015

(Conger, Kanungo \& Menon 2000, p. 751), and to question the status quo, long held values and expectations (Conger et al. 2000).

\section{Recognition-based Information Processing as a Theoretical Underpinnings}

To summarize the above literature, in the case of charismatic attribution through leader prototypes, group prototypes and archetypes, charisma is attributed to a leader when the leader's traits and behaviours match followers' leader prototypes, group prototypes or an archetype respectively, while in the case of leader extraordinariness it is the deviation of leader traits and behaviors from the followers' normative expectations of human beings (prototypical human beings) that provide the basis for charismatic attribution to that leader. In spite of this apparent contradiction between these two approaches, the underpinning mechanism of both attribution processes is one and the same, that is, recognition-based information processing. In both approaches, followers compare the perceived leader traits and behaviours of a leader with their normative expectations about the leader, i.e., prototypes/ archetypes. Accordingly, it can be concluded that leader prototypes, leader group prototypes, leader archetypes and leader extraordinariness can be grouped together because they all share the same underpinning-recognition-based information processing. Since the foundation of all these processes of charismatic attribution is one and the same, all processes can be expected to take place concurrently.

Although there is no evidence to support the argument that followers attribute charisma to alternative attribution processes operating concurrently a few studies attribute it to the interplay among several attribution processes. For instance, the empirical evidence indicates that both leader prototypicality and leader extraordinariness mute when the leader is group prototypical. First, followers who identify with the group are found to endorse leaders based on the group prototypicality of leaders whereas followers are likely to endorse leaders based on leader prototypes when they do not identify themselves with the group (Hais et al. 1997, Platow \& van Knippenberg 2001). Second, when a leader becomes leader group prototypical, the effect of self-sacrifice, a determinant of charisma related to extraordinariness, is found to become weak (van Knippenberg \& van Knippenberg 2005).

\section{Study Design}

This study takes the social constructionist approach to charisma, and thus assumes that a) charisma is constructed through interactions among social agents, b) multiple interpretations of charisma exist, c) the charisma of a leader is produced and reproduced on an ongoing 
basis, and finally d) the act of communication, including interviews the researcher had with research participants are the medium through which the research participants construct and negotiate the charisma of their leader.

The social constructionist approach permits the researcher to align his epistemological stance with the ontological stance of the follower-centric theory. It should be noted that all or most follower-centric researchers adopt the realist ontology in their empirical studies in spite of charisma being treated as 'constructed' by the beholders. According to Fairhurst and Grant (2010), the social constructionist approach endorses the attributional nature of charisma and is likely to accept leadership, i.e., charisma lies in the eye of the beholder, and thus matches the fundamental assumptions of the follower-centric theory. Furthermore, the social constructionist approach also accommodates the present study's bent towards the cognitive process, which Fairhurst and Grant (2010) treat as constructions of social reality.

\section{Case Sites}

The researcher selected two cases: a Project Team engaged in the implementation of an ERP system in a multinational company operating in Sri Lanka (which will be called SIN, hereafter) comprising six followers and a Senior Management Team of a telecommunication firm (known as MOB, hereafter) comprising again six followers. The Project Leader and the CEO who had turned around the business in each case are considered leaders in SIN and MOB respectively. In addition to taking each firm as a case, each dyad of leader and follower is also treated as a case since this paper treats charisma as a dyadic relationship between the individual follower and his/her leader.

While both case sites are characterized by change, MOB is also characterized by crisis. Both crisis and change are considered fertile grounds for the emergence of charisma (Conger 1999, Ladkin 2006). Furthermore, the leaders studied are socially close to the followers (Shamir 1995, Yagil, 1998). Shamir (1995), based on an exploratory content analysis of interviews, argues that the attribution of charisma to close leaders is based on recognitionbased information processing; Yagil (1998) too supports Shamir's position empirically. Accordingly, these two case sites can be considered 'best example cases' (Morse 2007, p. 234) and are in line with the qualitative research tradition that suggests selecting the best example case in which the phenomenon emerges 'more quickly and cleanly'.

The Project Director of SIN, Samaravithana joined the firm in 1986 after graduating from a Sri Lankan university and at the time of interviews he was serving as Director IT reporting 


\section{NSBM Journal of Management}

Vol. 1, No. 1, January - June, 2015

to the CEO. Samaravithana was recruited solely to set up the IT Division of the firm and is considered the person behind the ICT capability of the firm. All but one member of the Core Project Team were two or three levels below the CEO; the remaining follower, similar to Samaravithana, was a director reporting to the CEO. While three followers had a line relationship with Samaravithana, he had also been known to the other followers for several years.

A foreign company and a local partner established MOB in 1993 and it is relatively small. The local partner who was the leading fixed telephone operator in the country for decades became the sole owner of MOB in 2002. MOB had reported losses for years and Mahendra, who is considered the leader in the present study, joined MOB in 2005 as CEO and turned it around in less than three years. Mahendra is an engineer by profession and holds an MBA from the USA and counts many years of experience in the mobile phone industry, both locally and internationally. Except for two followers who had worked with him years before with another mobile phone operator in Sri Lanka, no one had heard about Mahendra before he joined MOB.

\section{Interview Process}

Following Stake (2005, p. 450), who states that disciplinary expectations guide the field work in multiple case studies, the researcher interviewed all followers in person with an interview guide based on the attribution processes discussed above. Interviews were held towards the end of Mahendra's fourth year at MOB, while the project of SIN had entered its final phase at the time of the interviews. All six members of the senior management team of MOB, and six of the eight members of the project team of SIN were interviewed. The interviews lasted approximately forty five minutes and were audio recorded and transcribed verbatim. All interviews (except one where the interviewee opted for Sinhala, his mother tongue) were conducted in English. All including the one who opted for Sinhala were good in English as a second language and English is the language of communication in both firms.

\section{Data Analysis Process}

Grounded theory method of data analysis was used as it offers '...practical advice of the nuts and bolts...' of analyzing data (Dey 2007, p.185). The researcher initially coded 'fragments' of an interview with a broader theoretical understanding of leadership rather than a theoretical formulation of charisma as advanced in the present paper. Then, following Kelle (2007, p. 193), the researcher reflected upon these codes and their representative fragments of 
interviews with the help of the present theoretical formulation of charisma. Accordingly, as suggested in the constructivist grounded theory, the theory emerged or was supported in the context of the present study through the researcher's close engagement in the interpretation of data rather than his 'close engagement with data' (Dey, 2007). Accordingly, the theoretical analysis of the present study can be considered an interpretative portrayal of reality (Charmaz 2005 , p. 510) grounded in the researcher's theoretical formulation of the research problem.

\section{Results and Discussion}

\section{Leader Prototypicality}

The interviews reveal that five followers at MOB and three followers at SIN attribute charisma to their leader in terms of leader prototypicality. Among the attributes, those known to be universally endorsed as leader attributes such as 'integrity', 'honesty' and 'vision' are found in the leader prototypes shared by these followers. For instance, MOBL1R3 states that:

... he should have a vision, he should have, you know, all the ingredients, you know, to encourage and to lead the people towards the vision. And he should be, you know... his integrity; I consider the integrity and honesty as the main...I think he is a very good CEO,... I don't see any issue...

Integrity and vision are identified in the GLOBE study as attributes of charismatic/value based leadership which are endorsed universally (Gupta et al. 2002). While the followers consider these attributes as attributes of 'good' (i.e., charismatic) leaders, they also see these attributes in their leader.

However, there are other attributes that these followers see in their leader which they do not consider as aspects of their prototypical leader, though they are considered as attributes of charismatic leader in the literature. For instance, while several followers in MOB state that their leader is inspirational, none of them considers inspiration as an attribute of their prototypical leader, though it is considered as an attribute of charismatic/value based leadership in the literature (Gupta et al. 2002). Consequently, inspirational behaviour that Mahendra is perceived to display cannot be expected to contribute to his charisma as it is not a part of his followers' leader prototypes in spite of it being considered as an attribute of charisma.

The followers of the present study are also found to possess culturally specific leader prototypes. An example of this is a somewhat authoritarian leader prototype attribute identified 


\section{NSBM Journal of Management}

Vol. 1, No. 1, January - June, 2015

in the talk of some followers. MOBL1R3 says that '...sometimes he is too nice to people, that's the issue...' Here, MOBL1R3 perceives Mahendra as a person who is sensitive towards people; however, he perceives this as an 'issue.' The phrase 'too nice' implies that MOBL1R3 expects to see the leader as a person who should be 'less sensitive towards others' feelings'. SINS1R4 pronounced this expectation strongly in his statement that ' ...the director I see is a rough guy... A person to whom you have to give what he asks for and who punishes when results are not there. But he is not like that'. If SINS1R4's reference to 'director' is interpreted as a reference to a leader, this can be taken to imply that SINS1R4 considers 'being strong' to be a leader prototypical attribute. Further, it can be concluded from MOBLR3's 'too nice' and SINS1R4's 'But he is not like that' that neither is likely to attribute charisma to their respective leaders because the latter do not measure up to their expectations of toughness. This expectation that the leader has to be 'strong' or 'less sensitive towards others' feelings' can be taken as a cultural phenomenon as previous studies indicate that Sri Lankan society is hierarchical (Nanayakkara 1992, Liyanage 1996) and respect for authority is a Sri Lankan cultural attribute (Nanayakkara 1992). Therefore,followers in Sri Lanka are said to expect their leaders to be '...autocratic, task-oriented, paternalistic...' (Upasena 1992, p. 177). These conclusions are in line with Den Hartog et al. (1999) and Hetland and Sandal (2003), who state that sensitivity might be considered as an aspect of feeble leadership in cultures which favour an authoritarian leadership style. Consequently, both of these leaders might be considered less charismatic in terms of that aspect and these findings can be considered as evidence of the impact of culture on prototype-based attribution of charisma.

Finally, the immediate task environment of the leader is also found to influence leader prototypes. For instance, SINL2R6 states '... if you take it in this context, now it has...he is one of the ideal people to handle this situation. He has taken it right...' while MOBL1R6 states '...I think he is very experienced; he had credential, he had qualification. He had everything right to sit as a CEO at MOB.' MOBL1R1states, 'I like to see this... it is there already. As far as I am concerned, there is nothing to look for beyond this. He has more capacity even to run a bigger organization than this.' All of these followers indicate that their leader is assessed against the ideal leader in the given task environment. While 'everything', 'nothing to look for beyond' and 'ideal leader' indicate use of the prototypical leader, 'if you take it in this context', 'sit as a CEO at MOB' and 'run a bigger organization than this' imply they form this prototypical leader in relation to the CEO's task environment and finally 'he had everything', 'it is there already' and 'he has more capacity' indicate that they perceive their leader to match their prototypical leader which makes Mahendra a charismatic leader in their eyes. 
The preceding discussion reveals that some of the attributes of leader prototypes are universal, others are culturally specific, and still others are specific to the immediate task environment. Consequently, while confirming the previous empirical evidence that leader prototypes embrace both universally and culturally salient leader attributes (Holmberg \& Akerbolm 2006), this study points to the fact that prototypical charisma is also linked to the immediate task environment. Additionally, the interviews also indicate that prototypes are used to classify a leader not only as a proper (positive -beyond the appropriate level) but also as an improper (negative -below the appropriate level) leader. Implications of the culture or the immediate task environment on prototypes or use of these prototypes as criteria to classify the leader as proper or improper have not been discussed in the current literature.

\section{Leader Archetypicality}

The analysis of the interviews also confirms the archetypical nature of charisma though the archetypes associated with the charisma of these leaders are different from each other. While the charisma attributed to Samaravithana by some of his followers can be considered paternalistic, none of Mahindra's followers perceived him as a paternalistic charismatic leader. Instead, Mahendra is seen as a missionary charismatic leader or a saviour by some of his followers. Paternalistic charisma refers to leaders who provide care and protection in exchange for submissive and dependent followership, saviour (Steyrer 1998) or saviour-like missionary charisma (Takala et al. 2012). That refers to charismatic leaders who transform or change social systems to a better one by offering a vision of a better future, strategies to realize it and mobilize followers towards that better future (Steyrer 1998, Takala et al. 2012).

While Samaravithana is perceived as a paternalistic charismatic leader, it seems that followers are unable to strongly or clearly articulate and tend to question their own perception. For instance, SINL2R6, who identified that Samaravithana possesses a fatherly image, seems uncertain about whether or not to consider Samaravithana as similar to his own parents.

...Let me...he is a father figure. He doesn't...OK...even when we go and have a drink...that is a different story. He is like a friend. But, he is a fatherly figure. He always comes and advises you, what to do with your family, sometimes he behaves that way also. But my parents...that is in a completely different way. I don't think...well I don't know it is. Because of my parents that I feel that way is quite possible...but I don't think... a lot of people can't come up to my parents' position. They are completely different people.... Mr. Samaravithana is younger than my parents. I don't think he can come up to their position...I don't... when he matures, he might come close to that... he is a very strong 


\section{NSBM Journal of Management}

Vol. 1, No. 1, January - June, 2015

leader. He has his own ideas and he tries to implement them. We have to work

for it. There are certain times that we were being pushed down. Mainly it was

for the best. He was not selfish or anything like that... (SINL2R6)

Even though there is some hesitancy indicated in the above statement, it contains some elements of paternalistic charisma. Paternalistic charisma is characterized by both softer values such as caring as well as hard values such as demanding and domination (Takala et al. 2012) and both aspects are embodied in the above quote. For instance, he states that Samaravithana advises even about family matters, while also saying that ' ... he has his own ideas and he tries to implement them. We have to work for it. There are certain times that we were being pushed down.' Accordingly, SINL2R6 appears to perceive that Samaravithana is concerned about the followers' family matters (soft values); on the other hand, he also perceives that followers have no option but to work for Samaravithana's ideas (hard values). Furthermore, the same quote shows that not only does the follower see the leader as a father but also attributes charisma to him as this follower says that ' $\mathrm{P} . .$. when he matures, he might come close to that... he is a very strong leader'.Hence, Samaravithana can be considered to be a paternalistic charismatic leader in the eyes of SINL2R6.

Although little has been written on contextual factors that support the emergence of paternalistic charisma, Takala et al. (2012) suggest that crisis incites followers to attribute paternalistic charisma. According to them, people can be expected to look for protection in times of crisis, and thus crises can be considered fertile ground for the emergence of paternalistic charisma since an element of protection is associated with paternalistic charisma. If this supposition is taken as valid, the charisma of Mahendra rather than of Samaravithana should be characterized by paternalism since MOB, and not SIN, is the firm that had gone through a period of crisis. Therefore, one might speculate whether this is to be taken as evidence to dispute Takala et al.'s argument; alternatively, it might be an indication of contextual influence. Some insight into this contradiction between the present findings and the literature on charisma can be gained when Sri Lankan culture is taken into account. For instance, previous studies have indicated that followers expect their leaders to be paternalistic (Upasena 1992). Consequently, the paternalistic charisma of Samaravithana might be a reflection of a general tendency of the Sri Lankan follower.

The literature also suggests that a crisis demands a leader to present a vision of a better future and strategies to realize it, which are the characteristics associated with saviourlike missionary charisma (Steyrer 1998, Takala et al. 2012). An archetype based on this requirement may have overshadowed the paternalistic aspects in the followers' attribution 
of charisma to Mahendra. This conclusion seems valid since the link between crisis and Mahendra's missionary charisma emerged plainly in the interviews.

... We were waiting for a CEO; he was very welcome...we were lagging behind market leaders by a greater distance. We were making losses. But we had the commitment. We have commitment...But, for the time being we had a setback. So, at that time we needed a CEO to rally around and really to strategize, re-strategize... (MOBL1R5)

...So, I thought we were a bit of a rudderless ship. We were wondering about... we had the ship, but did not have a captain. So, the ship can't go anywhere without the captain. So, I think he gave that captaincy or the pilot ship... (MOBL1R4)

The element of salvation attributed to Mahendra is not simply limited to overt recognition of Mahendra as a saviour. It is implied in the above interview excerpts. It also rests, as Steyrer (1998) suggested, in vision and transformation which are embedded in the strategies that Mahendra offered to deal with the crisis. For instance, a change in the pricing structure and the launch of a new product, both of which his followers identify as 'revolutionary' moves, support the fact that his vision and transformation are embedded in the strategies that he offered to overcome the crisis.

... the first thing that Mahendra did was to change that equation post to pre. Actually post-paid is difficult to manage. So, we got into prepaid. When we look at that time, all the others were $80 \%$ prepaid, $20 \%$ post-paid and some companies, I think $90 \%$, 95\% prepaid. We were actually $90 \%$ post-paid and $10 \%$ prepaid. Change of that equation, that's the first thing that Mahendra did. We launched a product called Seven Friends, which I think transformed the country's entire prepaid market... (MOBL1R3)

It should be noted that some literature suggests that followers tend to attribute successful business turnarounds to the incumbent CEO (Haslam et al. 2001), and such attribution is more likely to be inference-based regardless of the leader's contribution to success; this is the underpinning of the romance of leadership theory. Accordingly, it is important to separate the recognition-based attribution of saviour-like missionary charisma from the romanticization of the leader through performance cues. References to 'strategizing' and 're-strategizing' in the previous interview quotes suggest that MOBL1R5 directly links the organization's turnaround to specific actions of the leader rather than attributing the success to the leader 


\section{NSBM Journal of Management}

Vol. 1, No. 1, January - June, 2015

based on inferences; this is even clearer in the case of MOBL1R3, who explicitly names such strategies. Further, according to MOBL1R6, even when Mahendra made his inaugural speech, the employees of MOB who did not have a permanent CEO for around eight months and were looking for a CEO desperately had thought Mahendra was the right person to sit as CEO. Thus, the leader has been recognized as a saviour even before the unfolding of the success of the business. Accordingly, the attribution of Mahendra with saviour-like missionary charisma can be considered recognition-based, though later it could have been reinforced by the inference-based attribution; thus, his charisma can still be considered archetypical.

\section{Leader Extraordinariness}

The fourth cognitive element of the present conceptualization is the most prevalent element in both case sites. The followers expressed their perceptions of the extraordinariness of their leader in different words/phrases such as 'I have never seen a person like him' (SINS1R4), 'he is far ahead of many people' (SINL2R1), 'what a great person he is', (SINL2R1), 'Every day, for three years...following a task, keeping up that momentum...is unbelievable...' (SINL1R3), 'if you take a lot of people...if you take Sri Lanka, he is extraordinary' (SINL2R6), 'an extraordinary individual' (MOBL1R2), and 'one having a memory like an elephant' (MOBL1R4) and 'a special and outstanding person' (MOBL1R5).

While the use of the terms 'special', 'outstanding' and 'extraordinary' can be considered the follower's perception that the leader is set apart from the rest, 'the use of terms/phrases like 'unbelievable', 'what a great person' and 'never seen' can be taken to express the follower's perception of the leader as being transcendental. This indicates that the extraordinariness of a leader is perceived with different intensities and the intensity of charisma ranges, as Weber (1947)claims, from 'exceptionality', 'exemplariness' to 'a supernatural being', superhuman being'.

While these followers recognize leader extraordinariness in the very specific behaviours of their leaders, they also see leader extraordinariness in the leader's routine behavior. For instance, SINL2R1 recognizes the extraordinariness of Samaravithana in very specific task behaviour - his preparation for the application solution test.

... there was something called the application solution test. The required input data was brought by Mr. Samaravithana. Everything that is needed for the warehouse was there. He had brought things that even the people who work in the warehouse may not have remembered. WhenI understood that, I felt what a 
great person he is, because no one else would have done something like this... (SINL2R1)

The quotes from SINS2R2 and MOBL1R4 as stated below indicate that followers also see leader extraordinariness in his day-to-day routines. While SINS2R2's description of his leader, Samaravithana, can be considered an indication of perceived extraordinary commitment, MOBL1R4 attributes charisma to Mahendra for his extraordinary memory.

...he is heavily involved in all the aspects, top to bottom, even in the minor things, even simple errors, he records them and sends them before the implementation rather than waiting for the vendor to find and correct them, follows on the dot and ensures that it is being corrected and so on. That is the very, I think great thing... (SINS2R2)

...he has an extraordinary memory. He can recall years...an incident which has happened years back and say, no, look here this is not how it happened and this is how it happened. He has a memory like an elephant. I always say to my colleagues ...look here, if he says something, then think twice. Don't challenge his memory... (MOBL1R4)

Although leaders' extraordinary commitment is treated as an aspect of charisma in the present literature, extraordinary memory is not. In fact, the followers in both case sites stated many other behaviours such as success in personal/family life and being humble even after reaching the highest position in the organization, which are not considered as attributes of leader charisma in the present literature. These can be taken as indications of difficulty indentifying 'a constellation of behaviors' (Conger \& Kanungo 1987) as charismatic behavior and support for Jayakody's (2008, p. 837) argument '... what aloneis important in defining leader extraordinariness is 'apartness from the ordinary' but not what constitutes it'. In other words, charisma should be defined as a cognitive phenomenon of followers rather than a behavioral phenomenon of leaders.

Finally, it should be noted that the interviews indicate that extraordinariness is attributed to the leader even when he is perceived as an ordinary individual in certain other aspects. For instance, both SINL2R1 and SINL1R3, who perceive Samaravithana as an extraordinary individual also state that Samaravithana under certain circumstances panicked and even SINL1R3 went so far as to say that: 


\section{NSBM Journal of Management}

Vol. 1, No. 1, January - June, 2015

...Mr. Samaravithana panics. When I was at the Communion Bank, I learnt from Wijayaratne. He doesn't panic at all... Now when there is a problem, I do the balancing part of it. I have learnt that from the Communion Bank project...

According to SINL1R3's point of view, in respect of 'panicking', Samaravithana is an ordinary individual. Note how he states that in fact he is calmer compared to Samarawithana: 'Now, when there is a problem I do the balancing part.' Despite this, SINL1R3 still considers Samaravithana as an extraordinary individual due to some other qualities/behaviours that he perceives in Samaravithana. Thus, like what is observed in leader prototypicality, a leader is considered extraordinary along the line of some behaviours, while the same leader is considered ordinary in terms of other behaviours.

\section{Leader Group Prototypicality}

Leader group prototypicality is treated as the fourth element of the cognitive dimension of charisma. As discussed previously, the literature provides sufficient evidence for the group prototypes-based attribution of charisma. Yet, in contrast to this evidence in the literature, none of the followers in this study were found to attribute charisma based on the group prototypicality of the leader. The followers do not refer even to their group prototypes. Further exploration of the interviews suggests that the contextual factors are likely to overshadow the group prototypes-based attribution of charisma in both case sites; thus the leader group prototypicality can still be taken as an element of charisma.

As stated above, group prototypes are contextual and on the one hand, they are dependent on the salience of an out-group or on which out-group is salient (Hogg \& Terry 2000, van Knippenberg 2011), and the salience of the followers' group identity (Haiset al. 1997, Platow \&van Knippenberg 2001)on the other. Consequently, in any situations where a relevant outgroup is not salient and/or followers do not identify with the group, the charisma of the in-group leader cannot be expected to typify leader group prototypicality. If so, can weak salience of out-group and/or weak identification with the group be taken as a reason for the absence of leader group prototypicality of charisma in these leaders? The evidence suggests the case to be so.

The followers in neither SIN nor MOB refer to their organization as a community or a group and their competitors or other external parties as out-groups. Instead of possessing an identity based on their organizations, i.e., identifying with the organization, the followers especially in MOB see them as 'professionals' who have worked for or can work for their competitors 
in the future without a conflict of interest with their present employer. For instance, MOBL1R3, who once left for a competitor and re-joined MOB later, stated that he, as a professional, finds no issue of shifting between competitors. Furthermore, even though they identify themselves as 'professional', their out-group, non-processionals seem less salient as no reference is made during interviews to non-professionals. Therefore, the absence of group prototypicality-based attribution of charisma mightbeattributed to the lower salience of the out-group than taking it as evidence to dispute the argument that charisma is attributed to the leader when the leader matches the group prototypes of the followers.

\section{Charisma as a Constellation of Meanings}

In summary, this study shows that charisma is attributed to the leader not only by the recognition of his extraordinariness alone, which is the central theme in Weber's much popular definition and the sole basis of defining charisma in the neo-charismatic literature, or even, as the present follower-centric theories argue, not leader prototypes or leader archetypes or leader group prototypes alone. Instead, the attribution of charisma,as shown in the following figure, can take place through one or many of these processes concurrently, and thus charisma consists of several facets including leader extraordinariness, leader prototypicality, leader archetypicality and also group prototypicality or some of them.

Figure 1: Illustration of Charisma as a Constellation of Meanings

\begin{tabular}{clcccc}
\hline Leader & Follower & $\begin{array}{c}\text { Leader } \\
\text { prototypicality }\end{array}$ & $\begin{array}{c}\text { Leader group } \\
\text { prototypicality }\end{array}$ & $\begin{array}{c}\text { Leader } \\
\text { archetypicality }\end{array}$ & $\begin{array}{c}\text { Leader } \\
\text { extraordinarine }\end{array}$ \\
\hline Mahendra & MOBL1R 1 & $\checkmark$ & $\checkmark$ & $\checkmark$ \\
& MOBL1R2 & $\checkmark$ & & \\
& MOBL1R3 & $\checkmark$ & $\checkmark$ & $\checkmark$ \\
& MOBL1R4 & $\checkmark$ & $\checkmark$ & $\checkmark$ \\
& MOBL1R5 & & $\checkmark$ & $\checkmark$ \\
Samaravithana & & & $\checkmark$ \\
& MOBL1R6 & $\checkmark$ & & $\checkmark$ \\
& SINL2R1 & & & $\checkmark$ \\
& SINS1R2 & $\checkmark$ & $\checkmark$ & $\checkmark$ \\
& SINL1R3 & & & $\checkmark$ \\
& SINS1R4 & & $\checkmark$ & $\checkmark$ \\
\hline SINC1R5 & & & $\checkmark$ \\
& SINL2R6 & $\checkmark$ & & \\
\hline
\end{tabular}

The extracts from the interview with MOBL1R1given in Figure 1 illustratethat he attributes charisma to Mahendra along the line of leader prototypicality, leader archetypicality and 


\section{NSBM Journal of Management}

Vol. 1, No. 1, January - June, 2015

leader extraordinariness and not through just one of them, for instance, leader prototypicality. Furthermore, MOBL1R4, MOBL1R6 and SINL2R6attribute charisma through perceived leader prototypicality, leader archetypicality and leader extraordinariness, and thus support the argument that to these followers charisma means leader prototypicality, leader archetypicality and leader extraordinariness concurrently. Furthermore, SINS1R4 attributes charisma through leader archetypicality and leader extraordinariness and SINS1R2attributes charisma through leader prototypicality and leader extraordinariness. This indicates that followers use not only multiple attribution processes but in addition to that, they tend to use different processes.

The differences in attribution of charisma among followers of the same leader are not limited only to the attribution process that each follower uses. The differences can be seen in the behaviour or traits through which followers perceive each dimension, i.e., leader extraordinariness or leader prototypicality. For instance,MOBL1R1recognizes Mahendra as an extraordinary leader in terms of his 'workaholic' and 'extremely result oriented' behaviour, while MOBL1R4 recognizes the same in terms of 'extraordinary memory' and 'extraordinary personality'. MOBL1R3too recognizes Mahendra as an extraordinary leader but contrary to both MOBL1R1 andMOBL1R4, he perceives Mahendra's extraordinariness as he sees Mahendra' has not lost human qualities, even after reaching such a higher level'.

Accordingly, this study provides initial evidence for several insights on follower-centric charisma, especially in relation to its cognitive dimension. First, it illustrates that followers use multiple attribution processes concurrently, and the use of processes varies from follower to follower. Second, asaconsequence of the first point above, anumber of facets of charisma of the same leader varies from follower to follower; hence what each follower conceives as charisma varies from follower to follower. Finally, the study exemplifies that differentfollowers recognize leader charisma through different behaviors and traits of the same leader.

\section{Implications and Limitations}

\section{Theoretical Implications}

The aim of this paper is to provide some initial qualitative evidence in support of charisma as a constellation of meanings, especially its cognitive dimension, and thereby conceptualize charisma as a constellation of leader extraordinariness, leader group prototypicality, and leader prototypicality and leader archetypicality. Supporting this thesis, the present study shows that charisma does not exist in the eye of the follower only as a leader prototypical or a 
group prototypical or an archetypical or an extraordinary person that the previous researchers suggested but it exists as all or many of these forms concurrently.

In addition, the present study confirms the argument of Yagil (1998) that charisma is attributed even to close leaders and goes further to suggest that charisma is attributed to a leader through perceived extraordinariness even when the leader is perceived to be fallible in certain behaviours and qualities if he is perceived as extraordinary in other aspects.

Furthermore, these findings also contradict Weber's stance that charisma is unlikely to be found in everyday routine. Contrary to Weber's stand but in line with empirical evidence in Yorges, Weiss and Strickland (1999), this study indicates that followers tend to perceive leader extraordinariness in simple and routine day-to-activities such as, as shown above, 'recalling events' or 'sending emails'.

\section{Implications for Practice}

The present study has several practical implications. Firstly, it calls on managers to be aware of the possible implications of their own behaviour and traits on their charisma. The positive side of such implications is the possibility of leaders to manage their charisma by manipulating their own behaviour. Yet, the need for manipulating a wide spectrum of behaviours to match the situation makes the task difficult. This leads to the second implication-the need for leaders to be aware of their context- and its influence on their own charisma. These two implications signal leaders about the importance of self-awareness, sensitivity to the environment ranging from the immediate task environment to the followers' culture, the ability to read followers, and finally their own competence in impression management (Jayakody 2008, Riecher, Haslam \&Hopkins 2005). ,

\section{Limitations}

Overall, this study has the strengths and weaknesses generally associated with qualitative studies. For instance, as Braun and Clarke (2013, pp. 280-281) state, the generalization of findings has been cited as a limitation while the capacity to make a deep and rich interpretative analysis has been frequently celebrated. Since the purpose of the present study is to provide the initial evidence for an emerging theory rather than to examine the generalizability of a theory, the issue of generalization associated with qualitative research is less important compared to its strength to elaborate on the theory. Furthermore, as this paper takes the social constructionist approach which assumes multiple realities, generalization of findings cannot 


\section{NSBM Journal of Management}

Vol. 1, No. 1, January - June, 2015

be taken as an issue. Finally, as indicated above, since the context of leadership is likely to influence the attribution of charisma, it is the meaning of behaviour and qualities of the leader rather than behaviour and qualities themselves that are useful in understanding leadership dynamics in another situation.

\section{Conclusion}

There are a few areas that researchers shouldfurther explore. First, no evidence is found in this study to support or reject the notion that leader group prototypicality is an aspect of leader charisma. This, as stated above, may be due to the low salience of out-group in both cases. Therefore, researchers may explore this using more appropriate cases such as organizations which experience intense competition.

Second, this study excludes inference-based and affect (emotion)-based attribution of charisma in spite of their significance in understanding charisma. It should be noted that emotionally driven attribution of charisma lacks a sound theoretical foundation on which empirical work can be undertaken. Thus researchers first need to strengthen it. Towards this end, researchers may benefit from the currently available literature on emotional contagion (Bono \& Llies 2006), aesthetics of leadership (Ladkin 2008) and theoretical and empirical work (Wasielewski 1985, Johnson 2008) that examines the role of leader affect and arousal in charismatic attribution.

Finally, this study indicates the context such as task environment, crisis and culture influences attribution of charisma. Thus the researchers may also examine such influences. The connectionist framework can be suggested as an appropriate conceptual framework for such studies as Hanges, Lord and Dickson (2000) suggested.

\section{References}

Abramson, NR 2007, 'The leadership archetype: a Jungian analysis of similarities between modern leadership theory and Abraham myth in the Judaic-Christian tradition', Journal of Business Ethics, vol. 72, pp. 115-129.

Bono, R \& Lilies, JE 2006, 'Charisma, positive emotions and contagion.' The Leadership Quarterly, vol. 17, pp. 317-334.

Braun, V \& Clarke, V 2013, Successful qualitative research: apractical guide for beginners, Sage Publications, Thousand Oaks, CA.

Charmaz, K 2005, 'Grounded theory in the 21st century: applications for advancing social justice studies', in NK Denzin\& YS Lincoln (eds), The SAGE handbook of qualitative research, 3rdedn, pp. 507-536, Sage Publications, Thousand Oaks, CA. 
Conger, JA \& Kanungo, RN 1987, 'Towards a behavioural theory of charismatic leadership in organisational settings', Academy of Management Review, vol. 12, pp. 637-647.

Conger, JA 1999, 'Charismatic and transformational leadership in organizations: an insider's perspective on these developing streams of research', The Leadership Quarterly, vol.10, pp. 145-169.

Conger, JA, Kanungo, RN \& Menon, ST 2000, 'Charismatic leadership and follower affects,' Journal of Organizational Behaviour, vol. 21, pp. 747-767.

Den Hartog, D, House, RJ, Hanges, PJ \& Ruiz-Quintanilla, C 1999, 'Culture specific and crossculturally generalizable implicit leadership theories: are attributes of charismatic/transformational leadership universally endorsed?', The Leadership Quarterly, vol. 10, pp. 219-256.

Dey, I 2007, 'Grounding categories' in A Bryant \& K Charmaz (eds.), The SAGE handbook of grounded theory, Sage Publications, Thousand Oaks, CA.

Dickson, MW, Resick, CJ \&Hanges, PJ 2006, 'Systematic variation in organizationally-shared cognitive prototypes of effective leadership based on organizational form.' The Leadership Quarterly, vol. 17, pp. 487-505.

Eden, D \& Leviatan, U (1973), 'Implicit leadership theory as a determinant of the factor structure underlying supervisory behaviour scales', Journal of Applied Psychology, vol. 60, pp. 736-741.

Ensari, N \& Murphy, SE 2003, 'Cross-cultural variations in leadership perceptions and attribution of charisma to the leader', Organizational Behaviour and Human Decision Processes, vol. 92, pp. 52-66.

Fairhurst, GT \& Grant, D 2010, 'The social construction of leadership: a sailing guide.' Management Communication Quarterly, vol. 24, pp. 171-210.

Giessner, SR, van Knippenberg, D \& Sleebos, E 2009, License to fail? How leader group prototyplicality moderates the effects of leader performance on perceptions of leadership effectiveness', The Leadership Quarterly, vol. 20, pp. 434-451.

Greenfeld, L 1985, 'Reflections on two charismas', Journal of Sociology, vol. 36, pp. 117-132.

Gupta, V, Surie, G, Javidan, M \& Chhokar, J 2002, 'Southern Asia cluster: where the old meets the new?' Journal of World Business, vol. 37, pp. 16-27.

Hais, SC, Hogg, MA \& Duck, JM 1997, 'Self-organization and leadership: effects of group prototypicality and leader stereotypicality', Personality and Social Psychology Bulletin, vol. 23, pp. 1087-1099.

Hanges, PJ, Lord, RG \& Dickson, MW 2000, 'An information-processing perspective on leadership and culture: a case for connectionist architecture', Applied Psychology: An International Review, vol. 49, pp. 133-161.

Haslam, SA, Platow, MJ, Turner, JC, Reynolds, KJ, McGarty, C, Oakes, PJ, Johnson S, Ryan M \& Veenstra, K 2001, 'Social identity and the romance of leadership: the importance of being seen to be 'doing it for us". Group Process \& Intergroup Relations, vol. 4, pp. 191-205.

Hetland, H \& Sandal, GM 2003, 'Transformational leadership in Norway: outcomes and personality correlates'. European Journal of Work and Organizational Psychology, vol.12, pp. 147-170.

Hogg, MA \& Terry, DJ 2000, 'Social identity and self-categorization processes in organizational contexts', Academy of Management Review, vol. 25, pp. 121-140. 


\section{NSBM Journal of Management}

Vol. 1, No. 1, January - June, 2015

Hogg, MA 2001, 'A social identity theory of leadership'. Personality and Social Psychology Review, vol. 5, pp. 184-200.

Holmberg, I \& Akerblom, S 2006, 'Modelling leadership - implicit leadership theories in Sweden' Scandinavian Journal of Management, vol. 22, pp. 307-329.

Jayakody, JASK 2008, 'Charisma as a cognitive-affective phenomenon: a follower-centric approach', Management Decision, vol. 46, pp. 832-845.

Johnson, SK 2008, 'I secondthatemotion: effectsofemotional contagionandaffectatworkon leaderand follower outcomes', The Leadership Quarterly, vol. 19, pp. 1-19.

Jung, CG 1981, The Archetypes and the Collective Unconscious, Princeton University Press, Princeton.

Kelle, U 2007, The development of categories: different approaches in grounded theory in A. Bryant, \& K. Charmaz (eds.), The SAGE handbook of grounded theory (pp. 191-213), Sage Publications, Thousand Oaks, CA.

Keller, T 1999, 'Images of the familiar: individual differences and implicit leadership theories.' The Leadership Quarterly, vol. 10, pp. 580-607.

Kociatkiewicz, J \& Kostera, M 2012, 'The good manager: an archetypical quest for morally sustainable leadership.' Organization Studies, vol. 33, pp. 861-878.

Ladkin, D 2006, 'The enchantment of charismatic leader: charisma reconsidered as aesthetic encounter.' Leadership, vol. 2, pp. 165-179.

Ladkin, D 2008, 'Leading beautifully: how mastery, congruence and purpose create the aesthetic of embodied leadership practice', The Leadership Quarterly, vol. 19, pp. 31-41.

Liyanage, UP 1996, 'Profiling the emerging Sri Lankan consumer,' Sri Lankan Journal of Management, vol. 1, pp. 141-169.

Lord, RG \&Emrich, CG 2001, 'Thinking outside the box by looking inside the box: Extending the cognitive revolution in leadership research'. The Leadership Quarterly, vol.11, pp. 551-579.

Lord RG, Foti, RJ \& De Vader, C 1984, 'A test of leadership categorization theory: internal structure, information processing and leadership perceptions', Organizational Behavior and Human Performance, vol. 34, pp. 343-378.

Meindl, JR 1995, 'The romance of leadership as a follower-centric theory: a social constructionist approach.' The Leadership Quarterly, vol. 6, pp. 329-341.

Morse, JM 2007, 'Sampling in grounded theory' in A. Bryant, \& K. Charmaz (eds.), The SAGE handbook of grounded theory, pp. 229-244, Sage Publications, Thousand Oaks, CA.

Nanayakkara, G 1992, Culture and Management in Sri Lanka, PIM, Sri Lanka.

Nye, JL \& Forsyth, DR 1991, 'The effects of prototype-based biases on leadership appraisals: test of leadership categorization theory’. Small Group Research, vol.22, pp. 360-379.

Olsson, S 2000, 'Acknowledging the female archetype: woman managers' narratives of gender,' Woman in Management Review, vol. 15, pp. 296-302.

Platow, MJ \& van Knippenberg, D 2001, 'A social identity analysis of leadership endorsement: the effects of leader in-group prototypicality and distributive intergroup fairness', Personality and Social Psychology Bulletin, vol.27,pp. 1508-1519. 
Platow, MJ, van Knippenberg, D, Haslam, SA, van Knippenberg, B \& Spears, R 2006, 'A special gift we bestow on you for being representative of us: Considering leader charisma from a self-categorization perspective', The British Journal of Social Psychology, vol. 45, pp. 303-320.

Reicher, S, Haslam, A, \& Hopkins, N 2005, 'Social identity and dynamics of leadership: Leaders and followers as collaborative agents in the transformation of social reality', The Leadership Quarterly, vol.16, pp. 547-568.

Shamir, B 1995, 'Social distance and charisma: theoretical notes and exploratory study'. The Leadership Quarterly, vol.60, pp. 19-47.

Stake, RE 2005, 'Qualitative case studies', in N K Denzin, \& Y S Lincoln (eds.), The SAGE handbook of qualitative research 3rd edn, pp. 443-466, Sage Publications, Thousand Oaks, CA.

Steyrer, J 1998, 'Charisma and the archetypes of leadership', Organization Studies, vol. 19, pp. 807828.

Tee, EYJ, Paulsen, N \& Ashkanasy, NM 2013, 'Revisiting followership through a social identity perspective: the role of collective follower emotion and action', The Leadership Quarterly, vol. 24, pp. 902-918.

Takala, T, Tanttu, S, Lämsä, A \& Virtanes, A 2012, 'Discourses of charisma: Barrack Obama's first 6 months as the President of the USA', Journal of Business Ethics. Vol. 115, pp. 149-166.

Uhi-Bien, M, Riggio, RE, Lowe, KB, \& Carsten, MK 2014, 'Followership theory: a review and research agenda'. The Leadership Quarterly, vol. 25, pp. 83-104.

Upasena, KW 1992, 'Leadership styles and the task environment'.in G. Nanayakkara, (ed.) The Emerging Economic Order in Sri Lanka: Managerial Leadership, pp.177-191. PIM, Dehiwala, Sri Lanka.

vanKnippenberg, B \& van Knippenberg, D 2005, 'Leader self-sacrifice and leadership effectiveness: the moderating role of leader prototypicality', Journal of Applied Psychology, vol. 90,pp. 25-37.

vanKnippenberg, D 2011,'Embodying who we are: leader group prototypicality and leadership effectiveness', The Leadership Quarterly, vol. 22, pp. 1078-1091.

van Quaquebeke, N, van Knippenberg, D \& Brodbeck, FC 2011, 'More than meets the eye: the role of subordinates' self-perceptions in leader categorization process', The Leadership Quarterly, vol. 22, pp. 367-382.

Wasielewaki, P 1985, 'The emotional basis of charisma', Symbolic Interaction, vol.8, pp. 207- 222.

Weber, M 1947, The theory of social and economic organization, Free Press, USA.

Williams, JR 1988, Renewal theology: Systematic theology from charismatic perspective. Michigan, Zondervan PublishingHouse.

Yagil, D 1998, Charismatic leadership and organizational hierarchy: Attribution of charisma to close and distant leaders, The Leadership Quarterly, vol. 9, pp. 161-176.

Yorges, SL, Weiss, HM \& Strickland, OJ 1999, 'The effect of leader outcomes on influence, attributions, and perception of charisma', Journal of Applied Psychology, vol.84, pp. 428-436. 